\title{
Alterstice
}

Revue internationale de la recherche interculturelle

International Journal of Intercultural Research

Revista International de la Investigacion Intercultural

\section{Anthropologies de l'interculturalité, sous la direction de Anne Lavanchy, Anahy Gajardo et Fred Dervin}

\section{Alfredo Ramirez}

Volume 3, numéro 1, 2013

URI : https://id.erudit.org/iderudit/1077503ar

DOI : https://doi.org/10.7202/1077503ar

Aller au sommaire du numéro

Éditeur(s)

Alterstice

ISSN

1923-919X (numérique)

Découvrir la revue

Citer ce compte rendu

Ramirez, A. (2013). Compte rendu de [Anthropologies de l'interculturalité, sous la direction de Anne Lavanchy, Anahy Gajardo et Fred Dervin]. Alterstice, 3(1),

97-101. https://doi.org/10.7202/1077503ar d'utilisation que vous pouvez consulter en ligne.

https://apropos.erudit.org/fr/usagers/politique-dutilisation/ 


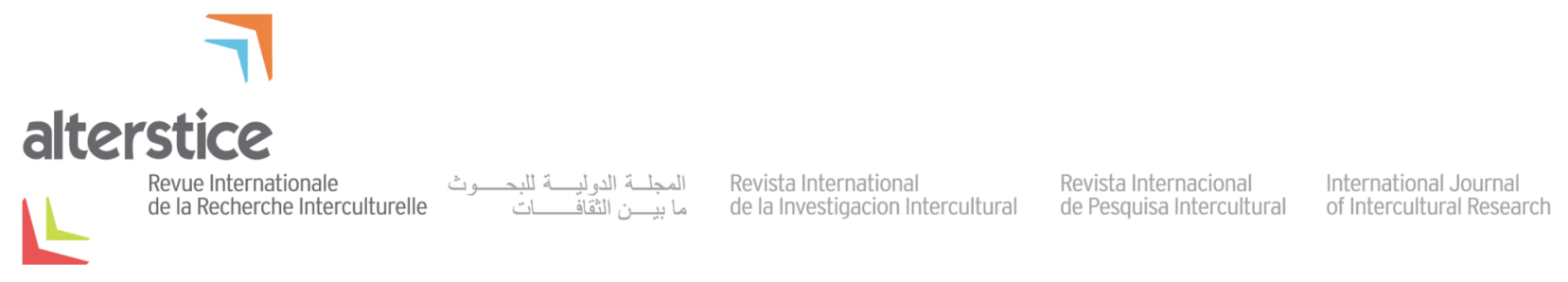

NOTE DE LECTURE

\title{
Anthropologies de l'interculturalité, sous la direction de Anne Lavanchy, Anahy Gajardo et Fred Dervin
}

Alfredo Ramirez ${ }^{1}$

\author{
Rattachement de l'auteur \\ ${ }^{1}$ Université Laval, Québec, Canada \\ Correspondance \\ alfredo.ramirez-villagra.1@ulaval.ca
}

\section{Références de l'ouvrage :}

Lavanchy, A., Gajardo, A. et Darvin, F. (2011). Anthropologies de l'interculturalité. Paris : L'Harmattan, 240 p.

\section{Pour citer cet article :}

Ramirez, A. (2013). Anthropologies de l'interculturalité [note de lecture]. Alterstice, 3(1), 97-101.

\begin{abstract}
Bien que l'étude de la rencontre entre cultures ait toujours été au cœur de l'anthropologie, le contexte actuel $d^{\prime}$ intenses déplacements humains sur toute la planète et les rencontres inédites qui en découlent génèrent de nouveaux sujets d'intérêt anthropologique. Par exemple, les modèles politiques d'intégration sociale développés en Occident et leurs pratiques de gestion de la diversité culturelle sont mis à l'épreuve par les mouvances migratoires. Pour mieux appréhender ces questions et arriver à articuler la rencontre contemporaine entre cultures, l'ouvrage collectif Anthropologies de l'interculturalité (2011), dirigé par Anne Lavanchy, Anahy Gajardo et Fred Dervin, invite à utiliser la notion d'interculturalité. Le livre est composé de six chapitres, auxquels s'ajoutent une introduction et une postface. Dans l'ensemble, les textes offrent un parcours critique de la notion d'interculturalité, autant en termes théoriques que pratiques.
\end{abstract}

Un des constats des auteurs est que l'utilisation du terme interculturel peut être vue comme une mode. De l'intervention sociale au marketing, en passant par l'éducation, la politique, l'académie et le tourisme, l'interculturel est utilisé sous différentes formes : "L'interculturel semble opérer comme une notion "caméléon", s'adaptant à divers champs d'application et véhiculant, sous le même terme, des conceptions et des pratiques non similaires, parfois non comparables ni compatibles, hormis le fait que toutes convoquent la notion de culture et portent leur attention sur ce qu'il se passe quand rencontre (inter-) il y a. » (p. 8) Les auteurs remarquent la facilité avec laquelle la notion d'interculturel est traduite sous la forme de discours et de pratiques hétéroclites, menant à un contact entre cultures porteur de différences ou d'universalismes plus ou moins artificiels. Ici, ce sont les dimensions politiques de l'utilisation de l'interculturel qui sont mises en évidence: «Omniprésent dans différents 
contextes, l'étude de l'usage du mot par le champ politique peut par exemple nous révéler des constructions des altérités et des projets d'une société idéalisée. » (p. 8)

L'établissement d'une généalogie de la notion d'interculturalité prend une place importante dans l'ouvrage. Dans l'introduction, les auteurs la conçoivent comme "une genèse plurielle » (p. 10), idée qui s'avère être une des contributions importantes de l'ouvrage. En effet, on y retrouve le rapport étroit entre science et politique, considéré comme déterminant pour l'émergence de l'interculturel. La formation à la communication interculturelle offerte aux diplomates étasuniens à la suite de la Seconde Guerre mondiale est considérée comme le point de départ du rapport science-politique, rapport qui s'est rapidement instauré dans d'autres milieux: "Cette double dimension, à l'image des deux faces d'une même médaille, se retrouve dans la plupart des champs où le terme est activé; à tel point qu'il est difficile - voir quasi impossible, de les dissocier dans l'analyse » (p. 11). Le Conseil de l'Europe est donné comme exemple de ce rapport en raison du fait que, dès 1970, il a élaboré des discours et des programmes décrivant l'interculturel comme une des manières de faire face au "nouveau défi » (p.11) des migrations en Europe.

Même si les balises données dans le livre quant à l'histoire de la notion d'interculturel sont certainement justes, on ne peut que regretter que les contours géographiques de cette généalogie restent limités aux exemples des ÉtatsUnis et de l'Europe. Au-delà de la mention ponctuelle de l'interculturalidad (p. 12) comme synonyme d'un projet politique particulier d'homogénéisation de la diversité en Amérique du Sud, des cas de figure comme le Brésil et le Québec sont ignorés. Pourtant, il s'agit de contextes où le rapport entre science et politique est hautement sensible et où la question interculturelle est depuis longtemps transversale aux débats politiques et aux politiques publiques.

Tous les chapitres du livre proposent des débats, d'ordres épistémologique, politique, éthique et pratique. En termes épistémologiques, la définition de la notion de culture reste centrale. Les divers discours et usages de l'interculturel amènent les auteurs à tenter d'élucider ce qu'est la culture, notamment lorsque l'interculturel est évoqué pour parler de l'Autre. Cette tentative clarificatrice est d'ailleurs le point de départ de chacune des contributions de l'ouvrage. Ainsi, l'interculturalité est définie comme une notion qui diffère de celle d'interculturel, cette dernière impliquant un a priori : "II y a des cultures différentes » (p. 15). C'est l'usage politique de la différence, "les politiques de l'altérité ", que les auteurs mettent en évidence : tout en se présentant comme des politiques interculturelles, ces discours visent à rencontrer un idéal type de société. " L'acculturation, l'assimilation et/ou l'intégration des personnes définies comme étrangères " peut être un des objectifs de ces politiques, mais il ne s'agit pas du même projet que de " créer une société nationale offrant des opportunités semblables à tou-te-s ses citoyen-ne-s » (p. 16). Les auteurs soulignent également que l'interculturel désigne une altérité " culturelle [où] s'effacent toute les caractéristiques d'identité sociale des interlocuteurs » (p. 17). Ces deux éléments, l'imposition d'une société idéale et le regarde monolithique sur les cultures, offrent un examen rigoureux de la notion de culture et conduisent Lavanchy, Gajardo et Dervin à proposer de privilégier l'utilisation du terme interculturalité, qui souligne "la dimension processuelle des rencontres" (p. 26) par opposition à la fixation déterministe et essentialiste des différentes cultures qui ressort de l'interculturel.

La première partie du livre aborde la tension entre l'universalisme et le relativisme. Le premier chapitre se penche sur les diverses approches utilisées dans le système éducatif européen pour la gestion de la diversité culturelle à I'intérieur des écoles. Selon les auteurs, Tania Ogay et Doris Edelmann, les diverses approches utilisées de 1970 à aujourd'hui sont clairement ethnocentriques, d'une part parce que les étudiants migrants ont été considérés à partir d'une approche d'altérité, et d'autre part parce que l'école en tant qu'institution est déjà porteuse d'une culture qui forme les étudiants. Pour leur part, Ogay et Edelmann proposent d'étudier la formation à l'interculturalité à partir de « la relation entre l'apprenant, le savoir et l'enseignant » (p. 53), de laquelle ressortent 
trois binômes : la relation apprenant-enseignant, la relation apprenant-savoir et la relation enseignant-savoir. Leur idée est de s'interroge sur l'interculturalité en éducation, de manière à remarquer qu'apprenant, enseignant et savoir peuvent référer à des contextes culturels différents. L'harmonisation de ces éléments ne résout pas nécessairement, cependant, les possibles tensions issues des différences culturelles. À partir de ce constat, les auteurs proposent de considérer les différences culturelles en fonction d'une relation dialectique, entre « égalité et diversité " (p.58). Ces deux notions doivent être observées en tenant compte de leurs opposés. Ainsi, égalité s'oppose à indifférence et diversité à culturalisation. La réflexion des enseignants quant à la manière de considérer les différences culturelles à partir d'une situation déterminée se situe à un point de croisement de ces deux continuums. Les considérations épistémiques relatives à cette méthodologie trouvent leur source dans la philosophie post-moderne. En questionnant les soubassements du savoir, cette approche offre une possibilité interprétative plus large que celle laissée par l'universalisme assimilationniste et le relativisme réductionniste. Bien que cet argument soit associé aux approches critiques, autant en anthropologie que dans d'autres disciplines, et qu'il se révèle utile à la remise en question du savoir universel tel que construit en Occident, les conclusions quant à la manière d'articuler la dialectique égalité/différence sont moins convaincantes. La question est résolue en revendiquant une interculturalité soucieuse de la justice sociale, une suggestion intéressante mais qui aurait gagné à être doublée d'une méthode de gestion pratique de la différence.

Le deuxième chapitre aborde une question d'ordre épistémique pour bâtir une approche interculturelle permettant de contourner le choix entre universalisme et relativisme lors de l'enseignement de la notion de droits de l'homme. L'auteur, Marc Debono, utilise la critique faite par les transculturalistes à l'endroit d'une certaine façon de comprendre l'interculturel (le «bienveillant», p. 75) pour explorer les limites des prétentions universalistes. En s'appuyant sur des initiatives qui élèvent le dialogue interculturel hors des espaces conflictuels de la rencontre de cultures, l'auteur présente ces pratiques comme étant contraires à la rencontre interculturelle. Préférant l'étude critique du transculturalisme, il présente la confrontation comme un élément facilitant la rencontre, puisque cette confrontation aide à considérer " une communauté de valeurs au-delà des cultures particulières » (p. 77). Toutefois, le transculturel n'échappe pas à l'universalisme lorsque la pédagogie des droits de l'homme est employée pour combattre le relativisme interculturel de certaines approches. Ceci amène Debono à se poser la question suivante : "N'est-ce pas tomber dans l'excès inverse de l'universalisme a priori et ethnocentré? 》 (p. 79) La proposition est donc d'aborder la notion des droits de l'homme sans renoncer au projet émancipateur qui est à leur origine, à partir d'un " commun », d'un "cadre pluraliste [donnant] la place à d'autres conceptions des droits humains" (p. 82). La construction du "commun» se fait à partir de la philosophie herméneutique, plus spécifiquement de l'herméneutique diatopique, qui amène une dimension d'échange de sens entre cultures différentes, la recherche de lieux communs de signification en termes rhétoriques (p. 91). L'exemple donné est le dialogue qui peut s'établir entre la notion des droits de l'homme et celle de dharma et d'umma (respectivement d'origine hindoue et islamique) (p. 93). Les espaces de significations et d'interactions créés à partir de cet exemple ouvrent la possibilité d'intégrer d'autres univers de significations, notamment dans les définitions des notions traditionnellement conceptualisées en Occident et qui imprègnent les discours et pratiques des relations contemporaines entre les cultures.

La deuxième partie du livre concerne la gestion politique de l'altérité. Laurent Bazin propose une analyse de «la place assignée à l'interculturalité dans les domaines d'intervention de l'État " à partir de l'étude discursive de différents textes officiels produits au cours des trente dernières années. L'auteur fait un parallèle avec le développement de l'éducation interculturelle, qui apparaît comme le résultat de "la pédagogie de la tolérance " (p. 103) soutenue par le Conseil de l'Europe. La France de 1978 commence à utiliser l'approche de l'éducation interculturelle, qui préconise "l'organisation d'activités interculturelles de l'école élémentaire au lycée » (p. 105). Néanmoins, l'auteur affirme que la France traduit cette notion différemment des institutions européennes. En fait, Bazin montre que les politiques d'État quant à la gestion de la diversité s'adaptent en fonction de l'utilisation de la notion d'interculturalité. En guise de réponse à la Convention de I'UNESCO sur la promotion de la diversité des expressions culturelles, l'État français fait omission de l'interculturalité et souligne son autonomie vis-à-vis des 
recommandations internationales « en mettant en avant le droit souverain des États de conserver, d'adopter et de mettre en œuvre les politiques et les mesures qu'ils jugent appropriées pour la protection et la promotion de la diversité des expressions culturelles sur leur territoire » (p. 109). Ce chapitre intéresse autant pour les résultats de l'analyse documentaire que pour l'historique de la notion d'interculturalité au sein de la France et du Conseil de l'Europe. Les conclusions de l'auteur soulignent l'ambiguïté de l'État par rapport aux discours politiques et aux législations qui se mettent en place, qui constituent une forme de colonialisme culturel à l'intérieur de l’Étatnation.

À partir de trois recherches menées en contexte helvétique, Laurence Ossipow examine dans son chapitre le rapport entre les notions de culture, d'interculturalité et de citoyenneté. Après un survol des différents débats autour de la notion de culture, Ossipow présente la culture à partir d'une approche interactionniste: "Les théoriciens interactionnistes s'attachent moins à définir la culture qu'à documenter des modes d'identification et d'assignation, référant à des traits culturels choisis ou imposés » (p. 130). Cette posture est reprise dans ses trois recherches. La première recherche traite du processus d'acquisition de la nationalité par des personnes ayant immigré en Suisse. L'auteur décrit la double allégeance des candidats, ce qui l’amène à définir la culture comme : « un héritage lié à la société ou à la famille d’origine [...] et comme un apprentissage lié au pays de résidence : la connaissance de la langue, des institutions, des lieux, des paysages, un nouveau réseau de relations, un autre métier [entre autres] » (p.134). La deuxième recherche montre la façon dont les membres de couples "binationaux» expriment leur "mixité », qu'ils associent le plus souvent à des différences culturelles. Ces différences sont construites comme une "ressource argumentative [...] et non comme un trait distinctif qui existerait en soi » (p. 139). La troisième recherche s'intéresse à la notion de citoyenneté. L'auteur présente le parcours théorique de diverses approches de cette notion et souligne le passage d'une citoyenneté technique à une citoyenneté inclusive des aspects culturels. Cette dernière posture est controversée car elle « tente de concilier astucieusement deux termes s'excluant, la citoyenneté étant en effet habituellement définie comme reposant sur un engagement commun faisant $\mathrm{fi}$ - en tout cas provisoirement et publiquement - de ses propres affinités et références ". Dans l'ensemble, l'auteur montre que penser le rapport entre culture et citoyenneté amène à des terrains où « se trouvent des formes de renouvellement du questionnement sur l'interculturalité » (p. 151).

La troisième et dernière partie du livre porte sur les usages et les pratiques discursives de l'interculturalité. Claudio Bolzman s'intéresse au processus d'affirmation identitaire des Chiliens exilés en Suisse entre les années 1980 et 2000. Partant de l'hypothèse que « les modes d'affirmation identitaire des Chiliens sont complexes et qu'ils ne se limitent pas à l'identification avec une culture nationale, celle de la société d'origine » (p. 159), l'auteur propose de comprendre l'interculturalité non seulement comme la relation entre cultures différentes au sein des groupes nationaux, mais aussi comme étant «constitutives des relations entre des groupes sociaux dans des situations sociohistoriques données » (p.160). C'est à partir de ce principe que l'auteur explore l'expérience d'exil des différents groupes de Chiliens qu'il interroge. Dans cette logique, il est intéressant de constater comment l'influence des expériences vécues avant l'exil pénètre la manière dont les interviewés se décrivent et dont ils définissent la culture qui les entoure. Lors de l'analyse du matériel recueilli, Bolzman fait le constat qu'il existe une «culture initiale de l'exil » (p. 166) qui « se modifie à travers le temps » (p. 167). Il établit ensuite une typologie des modes d'affirmation identitaire, croisant pour ce faire les valeurs d'importance «qui structurent la vie des interviewés [et] l'orientation spatiale de leurs pratiques représentatives » (ibidem). L'article réussit à bien à illustrer le fait que l'interculturel « est traversé par une dimension conflictuelle sous-jacente » : à expérience égale, dans un groupe qui partage apparemment une culture commune, les façons de concevoir et de vivre cette expérience rendent compte de considérations différentes en termes de valeurs. Cette complexité motive l'auteur à proposer un "travail d'explicitation, de part et d'autre" (p. 193) des situations qui rendent difficiles les relations interculturelles. Cette pratique devrait par ailleurs tenir compte « des contextes institutionnels et légaux qui définissent les conditions de l'interaction » (ibidem). 
Signé par Valerio Simoni, le dernier chapitre examine les discours associés à la culture et à l'interculturalité dans le cadre du tourisme sexuel à Cuba. L'auteur s'intéresse à la façon dont l'industrie touristique encadre une promotion de l'interculturel basée sur une vision spécifique du dialogue entre "visiteurs et visités » : "La connotation positive attribuée à l'expérience interculturelle en fait alors un outil conceptuel et un instrument rhétorique particulièrement efficace pour gérer, justifier, et rendre acceptables des pratiques potentiellement controversées ॥ (p. 198). Simoni met en évidence l'ambiguïté avec laquelle les touristes ayant des rencontres sexuelles rémunérées lors de séjours à Cuba expriment ce que signifie pour eux ce rapport. Le touriste décrit la rencontre interculturelle à partir de ce qui est promu par l'industrie touristique et de ce qui est vécu lors des rapports sexuels. L'articulation faite par les touristes de la notion de culture est amplement utilisée comme justification de leurs actes, laissant dans l'ombre les conditions structurelles qui sont à l'origine de ce rapport. Simoni explique comment se justifient ces pratiques sexuelles à partir de la promotion de l'interculturel en comparant le discours du gouvernement cubain sur la prostitution avant et après la révolution. Le phénomène du " jineterismo » est l'argument véhiculé : "Le jineterismo évoque l'image du Cubain/de la Cubaine qui chevauche le touriste étranger/la touriste étrangère par le biais de l'arnaque et de la commercialisation de relations sexuelles, afin de lui soustraire des ressources économiques ». (p. 206) Cette définition de la pratique sexuelle rémunérée est reprise par la plupart des entreprises de promotion de l'industrie touristique à l'international et consolide, sauf exception, une vision culturaliste de l'interculturel. L'article propose un examen de la tension existant entre une justification culturaliste de la prostitution visiteurs-visités et une autre axée sur les inégalités sociales. La première est plus répandue parce qu'elle permet " aux personnes impliquées de (re)formuler les cadres de justification de leurs pratiques sexuelles controversées, pour dépasser et résoudre des questionnements dérangeants de caractère éthique, moral, et identitaire, tout en rendant possible la déresponsabilisation et l'invisibilisation des inégalités socio-économiques " (p. 221).

Cet ouvrage s'avère offrir une importante contribution à l'anthropologie, car il aborde l'interculturel en définissant, décrivant et analysant différentes tensions présentes dans la rencontre contemporaine des cultures. L'ensemble des contributions montre bien la complexité des défis posés par l'interculturalité en termes épistémologiques, méthodologiques et pratiques. Cependant, une grande partie du livre peut aussi être lue comme une position de consensus quant au rôle joué par certaines instances européennes dans le développement de la notion d'interculturalité, ou encore quant au parcours de l'interculturel dans le domaine de l'éducation en Europe. 